\title{
PENERAPAN PENDIDIKAN KARAKTER OLEH MAHASISWA PENDIDIKAN KIMIA UIN SUNAN KALIJAGA
}

\author{
Kartika Angga Cahyaningsih ${ }^{1}$, Nani Arum Pratiwi ${ }^{2}$, Widiyanto ${ }^{3}$, Latief Susila Aji ${ }^{4}$, Mufrita \\ Laili $^{5}$, Muhammad Zamhari ${ }^{6, *}$ \\ 1,2,3,4,5,6 Pendidikan Kimia, Fakultas Ilmu Tarbiyah dan Keguruan, Universitas Islam Negeri Sunan \\ Kalijaga. Jl. Laksda Adisucipto, Papringan, Caturtunggal, Kec. Depok, Kabupaten Sleman, \\ Daerah Istimewa Yogyakarta 55281 \\ * Coressponding Author. E-mail: muhammad.zamhari@uin-suka.ac.id
}

Received: 13 Desember $2020 \quad$ Accepted: 31 Mei 2021

Published: 31 Mei 2021

doi: $10.29303 /$ cep.v4i1.2276

\begin{abstract}
Abstrak
Penelitian ini bertujuan untuk mengetahui pemahaman dan sikap mahasiswa terhadap penerapan pendidikan karakter di Prodi Pendidikan Kimia Universitas Islam Negeri (UIN) Sunan Kalijaga. Metode dalam penelitian ini adalah penelitian deskriptif melalui pendekatan kuantitatif dengan bantuan software SPSS 26.0 for windows. Populasi penelitian adalah mahasiswa Pendidikan Kimia yang berjumlah 198 mahasiswa dan diambil sampel sebanyak 72 mahasiswa $(36,36 \%)$ dengan teknik proportional random sampling. Variabel yang digunakan dalam penelitian ini adalah pemahaman dan sikap mahasiswa Prodi Pendidikan Kimia UIN Sunan Kalijaga terhadap implementasi pendidikan karakter. Hasil penelitian menunjukkan bahwa pemhaman dan sikap mahasiswa laki-laki Prodi Pendidikan Kimia UIN Sunan Kalijaga didominasi dalam kategori baik, yaitu sebesar $91 \%$, sedangkan kategori cukup baik hanya $9 \%$ dan untuk pemahaman dan sikap mahasiswa perempuan juga didominasi dalam kategori baik, yaitu sebesar 93,4\%, sedangkan kategori cukup hanya 6\%.
\end{abstract}

Kata Kunci: pendidikan karakter, pemahaman, sikap, implementasi

\section{Implementation of Character Education by Chemistry Education Students UIN Sunan Kalijaga}

\begin{abstract}
This study aims to determine the understanding and attitudes of students towards the application of character education in the Chemical Education Study Program of UIN Sunan Kalijaga. The method in this research is descriptive research through a quantitative approach with the help of SPSS 26.0 for windows. The study population was 198 students of Chemistry Education students with a sample of 72 students $(36.36 \%)$ with a proportional random sampling technique. The variables used in this study were the understanding and attitudes towards character education students in the Chemistry Education Study Program at UIN Sunan Kalijaga. The results showed that the understanding and attitudes of male students in the Chemistry Education Study Program of UIN Sunan Kalijaga were dominated in the good category, which was $91 \%$, while the good enough category was only $9 \%$ and the understanding and attitudes of female students were also dominated in the good category, which was $93.4 \%$, while only $6 \%$ in the sufficient category.
\end{abstract}

Keywords: character education, understanding, attitude, implementation 


\section{PENDAHULUAN}

Rendahnya karakter anak bangsa adalah suatu masalah krusial yang sedang dihadapi saat ini (Hadisi, 2016). Salah satu indikasinya adalah maraknya tindakan kriminalitas dan kekerasan (Dulkiah, 2018). Rendahnya karakter tidak hanya terjadi di lingkungan masyarakat, tetapi juga dalam dunia pendidikan(Zamhari \& Masamah, 2016). Lunturnya nilai-nilai budaya timuryang terjadi juga menjadi indikasi degradasi pendidikan karakter.Beberapa sikap sepertisopan santun, jujur, saling menghargai dan menghormati, tanggung jawab, adil, disiplin, kerja sama, kerja keras, dan peduli juga menurun di dunia pendidikan(Saliman, Widiastuti, \& Wulandari, 2013).

Pendidikan karakter merupakan proses pengubahan sikap dan perilaku seseorang atau kelompok dalam usaha mendewasakan manusia(Wahidin, 2013). Menurut Wahyudin (2009), pendidikan adalah humanisasi (upaya memanusiakan manusia) dan merupakan suatu upaya dalam rangka membantu manusia (peserta didik) agar mampu hidup sesuai dengan martabat kemanusiaannya. Pemerintah dalam UU RI No. 20 tahun 2003 pasal 3 secara khusus menyebutkan tentang pendidikan nasional berfungsi untuk mengembangkan kemampuan dan membentuk watak serta peradaban bangsa yang bermartabat dalam rangka mencerdaskan kehidupan bangsa. Serta dalam peraturan Kemendikbud RI No.20 Tahun 2018 yang mengatur tentang penguatan pendidikan karakter pada satuan pendidikan formal. Oleh karena itu, pendidikan karakter menjadi sebuah sistem penanaman nilai-nilai karakter kepada warga sekolah yang terdiri atas komponen pengetahuan, kesadaran atau kemauan dan tindakan untuk mengamalkan nilai-nilai tersebut baik terhadap Tuhan YME, diri sendiri, sesama, lingkungan maupun kebangsaan sehingga akan tercipta manusia insan kamil(Adu, 2014).Berdasarkan pendapat diatas, maka dapat diketahui bahwasanya pendidikan karakter tidak hanya berfokus pada usaha untuk memanusiakan manusia saja, akan tetapi juga terkait dengan hubungan dan perilaku kita terhadap Tuhan YME, diri sendiri, lingkungan, serta kebangsaan. Perilaku dan nilai-nilai moral, kebajikankebajikan, serta norma-norma dalam kehidupan sehari-hari sangat berhubungan erat dengan pendidikan karakter(Islam, 2017).

Pemahaman awal pendidikan karakter sangatlah penting untuk menumbuhkan karakter seseorang. Menurut Ilma (2015), pembentukan kepribadian sesorang membutuhkan tekad yang kuat dengan didorong oleh pemahaman dan kualitas SDM yang tinggi. Meskipun begitu, pergeseran budaya di masyarakat juga dapatmenyebabkan perubahan terhadap karakter setiap manusia.Oleh karena itu pendidikan karakter sangat dibutuhkan untuk menyeimbangkan antara perubahan karakter dengan pergeseran budaya yang terjadi (Zuhriy, 2011). Hal ini dapat dilakukan dengan menerapkan pendidikan karakter pada pendidikan formal, non-formal, dan informal yang mana komponen ini saling berhubungan satu sama lain. Sementara itu, sikap menurut Schwartz dalam Palupi dan Sawitri (2017) dinyatakan sebagai keyakinan yang diterjemahkan kedalam tindakan pada objek yang diinginkan. Sikap didefinisikan sebagai evaluasi positif atau negatif dari reaksi terhadap objek, orang, situasi atau aspek lain dan memungkinkan kita untuk memprediksi dan mengubah perilaku masyarakat. Kedua aspek ini sangatlah penting untuk dikembangkan dan juga diperbaiki apabila masih terdapat banyak kekurangan, terutama rusaknya karakter anak bangsa.

Langkah perbaikan karakter bangsa dapat dimulai dari dunia pendidikan(Zamhari \& Masamah, 2016). Dunia pendidikan mempunyai peran yang sangat penting dalam pembentukan generasi penerus bangsa. Undang-undang no 2 tahun 1989 tentang sistem pendidikan nasional telah mengarahkan pemerintah untuk memperhatikan pendidikan bangsa karena pendidikan memiliki kontribusi besar terhadap kemajuan suatu bangsa. Pembangunan karakter di bidang pendidikan juga harus terus dikembangkan untuk meningkatkan kualitas sumber daya manusia suatu negara agar mampu bersaing di era millennial (Suyanto dan Hisyam 2000).

Pendidikan karakter sebagaimana mestinya diterapkan oleh peserta didik maupun guru haruslah dapat diimplementasikan dengan baik. Peran tenaga pendidik merupakan salah satu faktor yang krusial. Menurut Masamah dan Zamhari (2016)secara hakiki tenaga pendidik memberikan pencerahan, baik itu mental maupun intelektual terhadap peserta didiknya melaluimateri yang diberikan dalam pembelajaran terkait dengan nilai-nilai karakter. Adapun beberapa contohnya adalah nilai cinta tanah air, cinta terhadap sesama manusia, dan nilai-nilai karakter lainnya(Suryaman, 2010) 
Beberapa penelitian tentang pendidikan karakter telah banyak diulas, salah satunya adalah penelitian yang dilakukan oleh Saliman dkk. (2013) yang menunjukkan bahwa persepsi mahasiswa Prodi Pendidikan IPS terhadap pelaksanaan Pendidikan karakter termasuk dalam kategori baik. Begitu juga dengan sikap mahasiswa Prodi Pendidikan IPS terhadap pendidikan karakter termasuk dalam kategori cukup baik. Sementara itu, penelitian yang terkait dengan implementasi pendidikan karakter yang dilakukan olehMaunah (2015), menunjukkan bahwa terdapat dua strategi dalam sistem pengelolaan pendidikan karakter, yaitu secara internal dan eksternal sekolah, dimana strategi internal sekolah dapat dilaukan dengan kegiatan belajar mengajar di kelas, kegiatan keseharian dalam bentuk school culture, kegiatan habituation, kegiatan ko-kurikuler, dan ekstrakurikuler. Sedangkan, strategi eksternalnya dapat dilakukan dengan kerjasama dengan orang tua serta masyarakat.

Pemahaman dan sikap dalam penerapan pendidikan karakter sangatlah penting. Terlebih, setiap individu maupun kelompok diberbagai daerah pasti memiliki perbedaan pemahaman dalam menginterpretasikan nilai-nilai dan sikap terkait penerapan pendidikan karakter di kehidupan sehari-harinya. Oleh karena itu peneliti melakukan penelitian mengenai pemahaman dan sikap mahasiswa Prodi Pendidikan Kimia UIN Sunan Kalijaga dalam mengimplementasikan pendidikan karakter, guna mengetahui pemahaman dan sikap tentang apa itu pendidikan karakter, apakah mahasiswa sudah memahami pendidikan karakter sejak dini, dan bagaimana bentuk implementasinya dalam kehidupan sehari-hari.

\section{METODE}

Berdasarkan masalah yang akan dibahas, penelitian ini termasuk penelitian deskriptif eksploratif, dimana hasil penelitiannya akan mendeskripsikan bagaimana pemahaman dan sikap pendidikan karakter mahasiswa Prodi Pendidikan Kimia UIN Sunan Kalijaga dalam kehidupan sehari- hari. Metode yang digunakan dalam penelitian ini adalah adaptasi metode kuantitatif dari penelitian yang dilakukan olehSaliman dkk. (2013). Pengolahan data mengunakan analisis statistik deskriptif dengan bantuan aplikasi SPSS 26.0 for windows. Analisis deskriptif merupakan bagian dari statistik yang mempelajari cara pengumpulan data sehingga mudah dipahami(Nasution, 2017). Penelitian ini dilakukan di Prodi Pendidikan Kimia Fakultas Sains dan Teknologi UIN Sunan Kalijaga pada bulan November 2019. Peneliti menggunakan satu variabel yaitu pemahaman dan sikap terhadap penerapan pendidikan karakter mahasiswa Prodi Pendidikan Kimia UIN Sunan Kalijaga.

Populasi dalam penelitian ini adalah 198 mahasiswa yang masih aktif sebagai mahasiswa sampai dengan Desember 2019 di Prodi Pendidikan Kimia UIN Sunan Kalijaga. Penelitian ini mengambil sampel sebanyak 72 mahasiswa atau $36,36 \%$ dari total populasi dengan teknikproportional random sampling. Teknik Pengumpulan data dari penelitian ini dilakukan dengan cara kuesioner online yang berisi seperangkat pertanyaan dan kemudian diisi oleh mahasiswa ProdiPendidikan Kimia UIN Sunan Kalijaga yang menjadi responden secara online.

Data diperoleh dengan membagikan instrumen berupa kuesioner melalui google form. Kuesioner tersebut diadaptasi dan dikembangkan dari penelitian Saliman dkk. (2013) yang terdiri dari sikap tanggung jawab, disiplin, kerja keras, kerja sama, sopan santun, percaya diri, dan keaktifan. Kuesioner memuat 31 pertanyaan dengan skala likert (Nasir, 1999)yang terdiri atas empat alternatif jawaban, Selalu, Sering, Jarang, Tidak Pernah. Konversi data dilakukan dengan merubah pernyataan kualitatif menjadi kuantitatif, selalu diberi nilai 4 , sering diberi nilai 3 , jarang diberi nilai 2, dan tidak pernah diberi nilai 1. Kemudian, hasil pengolahan data dianalisis yang terdiri dari pemahaman dan sikap berdasarkan presentase mahasiswa perempuan dan laki-laki dengan Analisis Statistika Deskriptif (ASD) yang meliputi mean, median, modus, standar deviasi, tabel distribusi frekuensi, dan kecenderungan skor.

Menurut Sutrisno Hadi dalam Saliman dkk. (2013) dari data yang diambil, dapat diperoleh kecenderungan skor masing-masing variabel dan dikategorikan sebagai berikut,

1. $>(\mathrm{M}+1 \mathrm{SDi})=$ tinggi $/$ baik

2. $(\mathrm{M}-1 \mathrm{SDi}) \mathrm{s} / \mathrm{d}(\mathrm{M} \mathrm{A}+1 \mathrm{SDi})=$ sedang/cukup baik

3. $(\mathrm{M}-1 \mathrm{SDi})=$ rendah/tidak baik dengan M sebagai Mean dan SDi sebagai standar deviasi.

Statistika deskriptif bertujuan untuk mencari proporsi serta frekuensi dari karakteristik subyek penelitian sehingga dapat menjawab pertanyaan apakah mahasiswa Prodi 
Pendidikan Kimia UIN Sunan Kalijaga sudah paham terhadap pendidikan karakter dan akrab dengan pendidikan karakter serta penerapanya di kehidupan sehari-hari.

\section{HASIL DAN PEMBAHASAN}

Data penelitian diambil pada bulan November 2019 dari 72 mahasiswa aktif Prodi Pendidikan Kimia UIN Sunan Kalijaga yang terdiri dari 11 mahasiswa dan 61 mahasiswi yang. Data diisi secara online melalui google form.Penelitian ini mengivestigasi pemahaman dan sikap pendidikan karakter mahasiswa Prodi Pendidikan Kimia UIN Sunan Kalijaga dalam kehidupan sehari- hari.

Penelitian ini menunjukkan bahwa pemahaman dan sikap mahasiswa pendidikan kimia sudah baik dalam mengimplementasikan pendidikan karakter dengan $47 \%$ dan $46 \%$ mahasiswa secara berturut-turut menyatakan bahwa mereka selalu dan sering menerapkan pendidikan karakter dalam kehidupan sehari-hari (Gambar 1 dan Tabel 1). Hanya sedikit mahasiswa (7\%) yang jarang menerapkan pendidikan karakter dalam kesehariannya dan tidak ditermukan mahasiswa yang tidak pernah menerapkan pendidikan karakter.

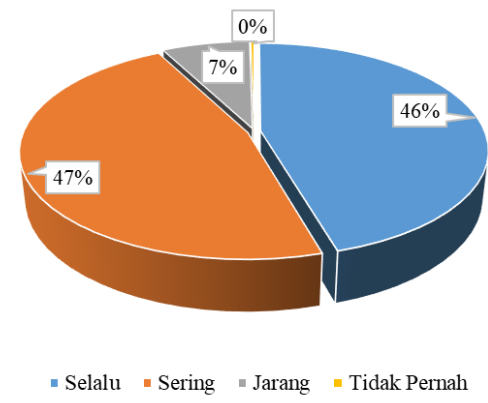

Gambar 1. Distribusi ResponPemahaman dan Sikap Pendidikan Karakter Mahasiswa Prodi Pendidikan Kimia UIN Sunan Kalijaga

Analisis lebih lanjut dilakukan dengan analisis statistik deskriptif (ASD) dengan bantuan SPSS 26.0 for windows. Tabel 2 menunjukkan deskripsi data yang meliputi skor maksimum, skor minimum, mean, median, modus, dan standar deviasi. Analisis tersebut menunjukkan mahasiswa perempuan memiliki nilai yang lebih tinggi daripada mahasiswa laki-laki. Hanya saja, pada deskripsi skor minimum mahasiswa perempuan lebih rendah. Hal ini membuktikan bahwa secara garis besar, mahasiswa perempuan memiliki pemahaman dan sikap yang lebih baik daripada mahasiswa laki-laki.

Tabel 3 menyajikan distribusi frekuensi untuk mahasiswa laki-laki pada sebanyak 11 mahasiswa dari interval skor 88-122dengan sebaran hampir merata. Hal ini menunjukkan, bahwasanya mahasiswa laki-laki tidak memiliki pemahaman dan sikap yang sama antara individu satu dengan lainnya. Distribusi frekuensi untuk mahasiswa perempuan pada Tabel 4 menyajikan sebaran 61 responden di rentang interval skor 88125. Data ini menggambarkan bahwa baik distribusi frekuensi mahasiswa laki-laki maupun perempuan memiliki kesamaan, yaitu perbedaan pemahaman dan sikap yang sama antara individu satu dengan lainnya dengan mayoritas ternilai baik (Tabel 5). Hal ini dikonfirmasi dengan pendapat dariSaliman dkk. (2013) yang menyatakan bahwa persepsi yang berbeda-beda tentang suatu objek, tergantung pada tingkat pemahaman dan interpretasi masing-masing individu terhadap objek tersebut. Hal ini diperkuat dengan penelitian yang dilakukan oleh (Setiawan, 2014) bahwa karakter/sikap merupakan cara berpikir dan berperilaku yang menjadi ciri khas tiap individu untuk hidup dan berkerjasama, baik dalam lingkungan keluarga, masyarakat, bangsa dan negara.

Analisis data pada tabel 5 menunjukkan bahwa $91 \%$ mahasiswa laki-laki memiliki pemahaman dan sikap dalam kategori baik, 9\% kategori cukup baik, serta $0 \%$ untuk kategori tidak baik. Sedangkan untuk mahasiswa perempuan, 93,4\% memiliki kategori baik dan 6,6\% dengan kategori cukup baik. Seperti halnya mahasiswa laki-laki, tidak ada mahasiswa perempuan dengan pemahaman dan sikap pendidikan karakter yang tidak baik. Hasil ini menunjukan bahwa mahasiswa perempuan memiliki pemahaman dan sikap yang baik berdasarkan dominasi kecenderungan skor responden yang paling banyak. Sekaligus membuktikan bahwa mahasiswa perempuan memiliki kecenderungan skor pemahaman dan sikap sedikit lebih tinggi daripada mahasiswa laki-laki. 
Chemistry Education Practice, 4 (1), 2021 - 102

Cahyaningsih, Pratiwi, Widiyanto, Aji, Laili, Zamhari

Tabel 1. Analisi Data Distribusi Kuesioner Pemahaman dan Sikap Pendidikan Karakter Mahasiswa Pendidikan Kimia UIN Sunan Kalijaga

\begin{tabular}{lccccc}
\hline $\begin{array}{l}\text { Pemahaman dan } \\
\text { Sikap }\end{array}$ & Nomor Soal & \multicolumn{4}{c}{ Persentase (\%) } \\
\cline { 3 - 5 } & & Selalu & Sering & Jarang & $\begin{array}{c}\text { Tidak } \\
\text { pernah }\end{array}$ \\
\hline Tanggung jawab & $1-4$ & 45,48 & 45,48 & 7,98 & 1,04 \\
Disiplin & $5-11$ & 68,05 & 31,15 & 0,79 & 0,00 \\
Kerja keras & $12-14$ & 36,52 & 56,48 & 6,01 & 0,46 \\
Kerja sama & $15-18$ & 47,22 & 47,91 & 4,51 & 0,00 \\
Sopan santun & $19-24$ & 37,26 & 57,87 & 4,86 & 0,00 \\
Aktif & $25-28$ & 25,34 & 52,77 & 20,83 & 0,34 \\
Ketelitian & $29-31$ & 57,87 & 35,18 & 6,94 & 0,00 \\
Rerata & & 45,39 & 46,69 & 7,42 & 0,26 \\
\hline
\end{tabular}

Tabel 2. Analisis Statistik Deskriptif Pemahaman dan Sikap Pendidikan Karakter Mahasiswa Pendidikan Kimia UIN Sunan Kalijaga Berdasarkan Jenis Kelamin

\begin{tabular}{lcc}
\hline \multirow{2}{*}{$\begin{array}{l}\text { Analisis Statistik } \\
\text { Deskriptif }\end{array}$} & \multicolumn{2}{c}{ Pemahaman dan Sikap } \\
\cline { 2 - 3 } & Laki-laki & Perempuan \\
\hline Skor Maksimum & 121.00 & 124.00 \\
Skor Minimum & 89.00 & 88.00 \\
Mean & 105.00 & 105.25 \\
Median & 102.00 & 106.00 \\
Modus & 102.00 & 107.00 \\
Standar Deviasi & 9.36 & 8.33 \\
\hline
\end{tabular}

Tabel 3. Distribusi Frekuensi Pemahaman dan SikapPendidikan Karakter Mahasiswa Laki-Laki Pendidikan Kimia UIN Sunan Kalijaga

\begin{tabular}{ccc}
\hline Interval & Frekuensi & $\begin{array}{c}\text { Persentase } \\
(\%)\end{array}$ \\
\hline $89-96$ & 1 & 9.1 \\
$97-105$ & 6 & 54.6 \\
$106-114$ & 2 & 18.2 \\
$115-122$ & 2 & 18.2 \\
Total & 11 & 100 \\
\hline
\end{tabular}

Tabel 4. Distribusi Frekuensi Pemahaman dan SikapPendidikan Karakter Mahasiswa Perempuan Pendidikan Kimia UIN Sunan Kalijaga

\begin{tabular}{ccc}
\hline Interval & Frekuensi & $\begin{array}{c}\text { Persentase } \\
(\boldsymbol{\%})\end{array}$ \\
\hline $88-92$ & 2 & 3.2 \\
$93-98$ & 14 & 23 \\
$99-104$ & 12 & 19.6 \\
$105-109$ & 13 & 21.4 \\
$110-115$ & 10 & 19.7 \\
$116-120$ & 5 & 8.1 \\
$121-125$ & 3 & 4.9 \\
Total & 61 & 100 \\
\hline
\end{tabular}

Tabel 5. Kecenderungan Skor Pemahaman dan Sikap Pendidikan Karakter Mahasiswa Pendidikan Kimia UIN Sunan KalijagaBerdasarkan Jenis Kelamin

\begin{tabular}{cccccc}
\hline \multirow{2}{*}{ Interval } & \multirow{2}{*}{ Kategori } & \multicolumn{3}{c}{ Frekuensi } & \multicolumn{2}{c}{ Persentase } \\
& & Lk & Pr & Lk & Pr \\
\hline \multirow{2}{*}{$>94$} & Baik & 10 & 57 & 91,0 & 93, \\
$62 \leq \mathrm{X} \leq 94$ & Cukup Baik & 1 & 4 & 9,0 & 6,6 \\
$<62$ & Tidak Baik & 0 & 0 & 0 & 0 \\
\hline
\end{tabular}

$\mathrm{Lk}=$ laki-laki, $\mathrm{Pr}=$ perempuan

Pelaksanaan pendidikan karakter sangat penting untuk mahasiswa Pendidikan Kimia. Sebagai calon pendidik, pendidikan karakter harus mulai ditanamkan sedini mungkin. Analisis Tabel 1lebih lanjut dilakukan oleh peneliti untuk menyajikan informasi lebih detail dari berbagai aspek, diantaranya adalah sebagai berikut:

1. Tanggung Jawab

Tanggung jawab merupakan sikap yang akan membuat seseorang mampu menyelesaikan tugas dengan baik. Sikap tanggung jawab ini juga yang menyadarkan seseorang untuk berani mengakui sebuah kesalahan. Mahasiswa pendidikan kimia UIN Sunan Kalijaga selalu diajarkan untuk bersikap penuh tanggung jawab, baik di kelas maupun di laboratorium. Seperti menyelesaikan tugas dengan baik, melakukan praktikum sesuai dengan cara kerja, membereskan dan membersihkan laboratorium setelah digunakan. Hasil penelitian dapat diketahui bahwa pemahaman dan sikap tanggung jawab mahasiswa Prodi Pendidikan Kimia UIN Sunan Kalijaga sudah baik, hal ini ditunjukkan pada persentase jawaban "Selalu" dan "Sering" memiliki nilai yang sama serta keduanya mendominasi daripada jawaban "Jarang" dan "Tidak Pernah", dimana jawaban soal nomor 1 sampai 4, jawaban "Selalu" sebanyak 45,48\%, 
jawaban "Sering" 45,48\%, jawaban "Jarang" $7,98 \%$, dan sisanya adalah jawaban 'Tidak Pernah' $1,04 \%$.

2. Disiplin

Disiplin merupakan sikap taat dan patuh kepada peraturan yang berlaku. Sikap disiplin di lingkungan Prodi Pendidikan Kimia UIN Sunan Kalijaga dilaksanakan secara terus menerus dengan mentaati peraturan-peraturan akademik, kontrak belajar dengan dosen, maupun dari laboratorium, seperti datang tepat waktu, menggunakan jas laboratorium, menggunakan alat keamanan, dan mengerjakan tugas tepat waktu. Sikap disiplin mahasiswa pendidikan kimia UIN Sunan Kalijaga sudah baik, hal ini ditunjukkan dengan tidak adanya jawaban "Tidak Pernah" $0 \%$ pada soal nomor 5 sampai nomor 11 . Jawaban terbanyak adalah "Selalu' yang semakin menguatkan bahwa pemahaman dan sikap disiplin mahasiswa Prodi Pendidikan Kimia UIN Sunan Kalijaga sudah baik, yaitu sebesar $68,05 \%$; sedangkan untuk jawaban "Sering" 31,15\%, dan sisanya adalah jawaban "Jarang" $0,79 \%$.

\section{Kerja Keras}

Kerja keras harus selalu diterapkan dalam kehidupan sehari-hari. Dengan sikap kerja keras, akan membuahkan hasil yang maksimal. Kerja keras juga akan membuat seseorang tidak mudah menyerah. Sikap ini sangat diperlukan oleh mahasiswa pendidikan kimia sebagai calon pendidik. Sikap kerja keras mahasiswa Prodi Pendidikan Kimia UIN Sunan Kalijaga sudah baik, hal ini ditunjukkan pada persentase jawaban "Selalu" dan "Sering" yang mendominasi daripada jawaban "Jarang" dan "Tidak Pernah", dimana jawaban soal nomor 12-14, yaitu jawaban "Selalu" sebesar 36,52\%, jawaban "Sering" $56,48 \%$, jawaban "Jarang" $6,01 \%$, dan sisanya adalah jawaban "Tidak Pernah' 0,46\%.

4. Kerjasama

Kerjasama sangat penting bagi mahasiswa dalam bersosialisasi. Sikap peduli dan saling tolong menolong yang sudah mulai tergerus zaman ini terus digalakkan dalam lingkungan Prodi Pendidikan Kimia UIN Sunan Kalijaga baik di kelas maupun di laboratorium. Hal ini diwujudkan dalam proses pembelajaran, mahasiswa dibentuk kelompok untuk menyelesaikan tugas. Begitu juga di laboratorium, mahasiswa dilatih untuk bekerja sama dengan kelompoknya dalam melakukan praktikum. Mahasiswa Prodi Pendidikan Kimia UIN Sunan Kalijaga memiliki sikap kerja sama yang baik, hal ini ditunjukkan dengan tidak adanya jawaban "Tidak Pernah" dan persentase jawaban "Selalu" dan "Sering" yang mendominasi daripada jawaban "Jarang" dan "Tidak Pernah", dimana jawaban soal nomor 1518, yaitu jawaban "Selalu" sebesar 47,22\%, jawaban "Sering" 47,91\%, dan sisanya jawaban "Jarang" 4,51\%.

\section{Sopan Santun}

Sopan santun merupakan sikap yang dibanggakan masyarakat Indonesia sebagai bangsa timur. Ramah tamah, murah senyum, saling menyapa, kesopanan, saling menghormati, dan cara berpakaian yang rapi dan sopan merupakan budaya yang patut dilestarikan. Sikap sopan santun yang sudah mulai pudar seiring berkembangnya teknologi informasi. Berbagai tayangan di media sosial banyak memberikan contoh-contoh negatif yang justru banyak ditiru masyarakat. Pembudayaan sikap sopan santun perlu adanya kerja sama dari berbagai elemen masyarakat. Oleh karena itu, pembudayaan ini harus dimulai dari lingkup terkecil, seperti lingkungan keluarga dan lingkungan akademis. Pembudayaan sikap sopan santun di lingkungan Prodi Pendidikan Kimia UIN Sunan Kalijaga ini sudah berjalan baik, hal ini ditunjukkan pada persentase jawaban "Selalu" dan "Sering" yang mendominasi daripada jawaban "Jarang" dan "Tidak Pernah", dimana jawaban soal nomor 1924, yaitu jawaban "Selalu" sebessar 37,26\%, jawaban "Sering" $57,87 \%$, dan sisanya jawaban 'jarang' 4,86\%.

\section{Aktif}

Sikap aktif akan meningkatkan kualitas kinerja seseorang. Dengan memiliki sikap aktif, seorang mahasiswa akan menghasilkan tindakan yang nyata. Sikap aktif ini juga menjadi tuntutan bagi mahasiswa, baik di kelas ketika proses belajar maupun di laboratorium ketika praktikum. Mahasiswa Prodi Pendidikan Kimia UIN Sunan Kalijaga telah menerapkan sikap aktif dengan baik. Hal ini ditunjukkan pada persentase jawaban "Selalu" dan "Sering" yang mendominasi daripada jawaban "Jarang" dan "Tidak Pernah", dimana jawaban soal nomor 2528, yaitu sebanyak jawaban "Selalu" sebesar $25,34 \%$, jawaban "Sering" 52,77\%, jawaban "Jarang" 20,83\%, dan sisanya jawaban "Tidak Pernah" 0,34\%.

\section{Ketelitian}

Ketelitian merupakan sikap seorang tenaga pendidikan. Sikap ketelitian ini sangat diperlukan mahasiswa pendidikan kimia baik di kelas maupun di laboratorium. Sebagai contoh, mahasiswa meneliti terlebih dahulu pekerjaannya sebelum dikumpulkan ke dosen, melakukan 
praktikum dengan cermat sehingga tidak terjadi kesalahan, mengecek ulang alat-alat praktikum yang digunakan, dan sebagainya. Mahasiswa Prodi Pendidikan Kimia UIN Sunan Kalijaga menerapkan sikap teliti dengan baik. Hal ini ditunjukkan pada persentase jawaban "Selalu" dan "Sering" yang mendominasi daripada jawaban "Jarang" dan "Tidak Pernah", dimana jawaban soal nomor 29 sampai 31, yaitu jawaban "Selalu" sebesar 57,87\%, jawaban "Sering" $35,18 \%$, dan sisanya jawaban "jarang" 6,94\%.

Berdasarkan uraian di atas, maka terlihat bahwa pemahaman dan sikap mahasiswa Prodi Pendidikan Kimia UIN Sunan Kalijaga sudah baik. Hasil ini tentunya dapat menggambarkan bahwa watak dan kepribadian mahasiwa sudah tertata dengan baik yang ditandai sebagai keberhasilan dalam menerapkan pendidikan karakter di kehidupan sehari-hari. Sebagaimana penelitian sebelumnya yang telah dilakukan oleh (Islam, 2017) menyimpulkan bahwa pendidikan karakter yang merupakan usaha sadar yang dilakukan secara sistematis melalui proses pembelajaran yang mengembangkan seluruh potensi manusia agar memiliki watak dan kepribadian yang baik, bermoral-berakhlak, dan berefek positif konstruktif pada alam dan masyarakat.

\section{SIMPULAN}

Simpulan dapat bersifat generalisasi temuan sesuai permasalahan penelitian, dapat pula berupa rekomendatif untuk langkah selanjutnya.Berdasarkan hasil analisis data penelitian yang telah dilakukan, maka dapat disimpulkan bahwa analisis statistik deskriptif (ASD) terhadap pemahaman dan sikap mahasiswa Prodi Pendidikan Kimia UIN Sunan kalijaga, dapat diketahui bahwa secara keseluruhan mahasiswa perempuan dan laki-laki berada dalam kategori baik. Namun, berdasarkan analisis, mahasiswa perempuan memiliki kecenderungan skor yang lebih tinggi daripada mahasiswa laki-laki, yaitu kategori baik sebesar 91\% dan cukup baik 9\%, sedangkan mahasiswa perempuan kategori baik sebesar $93.4 \%$ dan cukup baik $6.6 \%$. Pemahaman dan sikap terhadap penerapan pendidikan karakter mahasiswa Prodi Pendidikan Kimia UIN Sunan Kalijaga sudah baik. Implementasi pendidikan karakter tersebut terdiri atas sikap tanggung jawab, disiplin, kerja sama, sopan santun, percaya diri, dan keaktifan. Masing-masing sikap tersebut sudah diimplementasikan dengan baik oleh mahasiswa UIN Sunan Kalijaga di dalam kehidupan seharihari terutama di lingkungan kampus. Implementasi tersebut menunjukkan bahwa tidak hanya pemahaman dan sikap mengenai pendidikan karakter dikalangan mahasiswa Prodi Pendidikan Kimia UIN Sunan Kalijaga yang begitu baik, akan tetapi juga anggapan pentingnya pendidikan karakter yang begitu besar.

\section{DAFTAR PUSTAKA}

Adu, L. (2014). Pendidikan karakter dalam perspektif Islam. BIOSEL (Biology Science and Education): Jurnal Penelitian Science dan Pendidikan, 3(1), 68-78.

Dulkiah, M. (2018). Pengaruh Kemiskinan Terhadap Tingkat Tindak Kriminalitas Di Kota Bandung. JISPO Jurnal Ilmu Sosial dan Ilmu Politik, 8(1), 36-57.

Hadisi, L. (2016). Efektifitas Pendidikan Karakter Pada Sekolah Anak Usia Dini: Studi PadaTK Islam Terpadu Al-Qalam Kendari. Al-Izzah: Jurnal Hasil-Hasil Penelitian, 11(2), 109-125. doi:10.31332/ai.v11i2.457

Ilma, N. (2015). Peran Pendidikan Sebagai Modal Utama Membangun Karakter Bangsa. Tadbir: Jurnal Manajemen Pendidikan Islam, 3(1), 82-87.

Islam, S. (2017). Karakteristik pendidikan karakter; menjawab tantangan multidimensional melalui implementasi Kurikulum 2013. EDURELIGIA: Jurnal Pendidikan Agama Islam, 1(1), 89-100.

Masamah, U., \& Zamhari, M. (2016). Peran Guru Dalam Membangunan Pendidikan Berkesadaran Multikultural Di Indonesia. Quality, 4(2), 262-279. doi:10.21043/quality.v4i2.2124

Maunah, B. (2015). Implementasi pendidikan karakter dalam pembentukan kepribadian holistik siswa. Jurnal Pendidikan Karakter(1), 90-101.

Nasir, M. (1999). Metode Penelitian. Jakarta: Ghalia Indonesia.

Nasution, L. M. (2017). Statistik deskriptif. Hikmah, 14(1), 49-55.

Palupi, T., \& Sawitri, D. R. (2017). Hubungan antara sikap dengan perilaku prolingkungan ditinjau dari perspektif theory of planned behavior. Paper presented at the Proceeding Biology 
Chemistry Education Practice, 4 (1), 2021 - 105

Cahyaningsih, Pratiwi, Widiyanto, Aji, Laili, Zamhari

Education Conference: Biology, Science,

Enviromental, and Learning.

Saliman, Widiastuti, A., \& Wulandari, T. (2013). Persepsi dan Sikap Mahasiswa Terhadap Pendidikan Karakter di Prodi Pendidikan IPS UNY. SOCIA: Jurnal Ilmu-Ilmu Sosial, $\quad 10(2), \quad 139-146$. doi:10.21831/socia.v10i2.5350

Setiawan, A. (2014). Prinsip pendidikan karakter dalam islam: studi komparasi pemikiran al-Ghazali dan Burhanuddin al-Zarnuji. Dinamika Ilmu, 14(1), 1-12. doi:10.21093/di.v14i1.4

Suryaman, M. (2010). Pendidikan karakter melalui pembelajaran sastra. Jurnal Cakrawala Pendidikan, 1(3), 112-126.

Wahidin, U. (2013). Pendidikan Karakter Bagi Remaja. Edukasi Islami: Jurnal Pendidikan Islam, 2(3), 256-269. doi:10.30868/ei.v2i03.29

Wahyudin, D. (2009). Pengantar Pendidikan. Jakarta: Universitas Terbuka.

Zamhari, M., \& Masamah, U. (2016). Relevansi metode pembentukan pendidikan karakter dalam kitab Ta'lim alMuta'allim terhadap dunia pendidikan modern. Edukasia: Jurnal Penelitian Pendidikan Islam, 11(2), 421-442. doi:10.21043/edukasia.v11i2.1724

Zuhriy, M. S. (2011). Budaya pesantren dan pendidikan karakter pada pondok pesantren salaf. Walisongo: Jurnal Penelitian Sosial Keagamaan, 19(2), 287-310. doi:10.21580/ws.19.2.159 